\title{
Large Area Silicon Drift Detectors for EDS in Microbeam Analysis
}

\author{
H.Soltau, ${ }^{*}$ P.Lechner, ${ }^{*}$ G. Lutz, ${ }^{*}$ A. Niculae, ${ }^{*}$ L. Strüder, ${ }^{* *}$ C. Fiorini*** and A. Longoni *** \\ R. Eckhard, ${ }^{*}$ G. Schaller, ${ }^{* *}$ and F. Schopper**
}

*PNSensor GmbH, Römerstr. 28, D-80803 München, Germany

**MPI Halbleiterlabor, Otto-Hahn-Ring 6, D-81739 München, Germany

****Politecnico di Milano, Piazza L. da Vinci 32, I-20133 Milano, Italy

Silicon Drift Detectors (SDDs) with integrated first amplification step are fabricated by the Semiconductor Laboratory of the Max-Planck-Institute in Munich in cooperation with PNSensor. They are used for EDS in Microbeam and XRF Analysis with active areas of $5 \mathrm{~mm}^{2}$ and $10 \mathrm{~mm}^{2}$.

Larger active area devices are of interest for many applications as they enhance quantum efficiency and reduce throughput time.

For these needs two courses are followed: on one side, large area single SDDs with sizes of 20 and $30 \mathrm{~mm}^{2}$ are fabricated and qualified; on the other side multielement devices comprising overall active areas of $40 \mathrm{~mm}^{2}$ up to $5 \mathrm{~cm}^{2}$ and cell sizes between 5 and $15 \mathrm{~mm}^{2}$ have been developed and operated (see Fig.1).

For a scientific experiment at the $\mathrm{e}^{+} \mathrm{e}^{-}$collider DAФNE in Frascati, Italy the two approaches have been combined leading to detectors of $1 \mathrm{~cm}^{2}$ size monolithically assembled into strips with an overall sensitive area of $200 \mathrm{~cm}^{2}$ (see Fig.2). Read out of the chips will be performed by means of ASICs operated in CSA mode.

It is the main objective in large area SDD production to keep the good performance of the device close to room temperature, easily to be achieved with single or double stage peltier cooling. Therefore a new fabrication technology has been developed improving leakage current control. Fig. 3 shows the excellent performance of the as-produced detectors demonstrating energy resolution values better than $135 \mathrm{eV}$ at $-30^{\circ} \mathrm{C}$ for 20 and $30 \mathrm{~mm}^{2}$. Tab. 1 summarizes the measurement results:

\begin{tabular}{|c|c|c|c|}
\hline \multirow[t]{2}{*}{ Type } & Active Volume & Energy Resolution@-20 $\mathrm{C}$ & \multirow{2}{*}{$\begin{array}{c}\text { Peak-to-Background } \\
\text { Ratio }\end{array}$} \\
\hline & Chip Format & Energy Resolution@-30 $\mathrm{C}$ & \\
\hline \multirow[t]{2}{*}{ SDD-20-150 } & $20.0 \mathrm{~mm}^{2} \times 450 \mu \mathrm{m}$ & $145 \mathrm{eV}-150 \mathrm{eV}$ & \multirow[t]{2}{*}{ typ. 3.000-5.000 } \\
\hline & $8 \times 8 \mathrm{~mm}^{2}$ & $135 \mathrm{eV}-140 \mathrm{eV}$ & \\
\hline \multirow[t]{2}{*}{ SDD-30-160 } & $30.0 \mathrm{~mm}^{2} \times 450 \mu \mathrm{m}$ & $155 \mathrm{eV}-160 \mathrm{eV}$ & \multirow[t]{2}{*}{ typ. 3.000-5.000 } \\
\hline & $9 \times 9 \mathrm{~mm}^{2}$ & $140 \mathrm{eV}-145 \mathrm{eV}$ & \\
\hline \multirow{2}{*}{$\begin{array}{l}\text { PSD-20-135 } \\
\text { new technology }\end{array}$} & $20.0 \mathrm{~mm}^{2} \times 450 \mu \mathrm{m}$ & typ. $135 \mathrm{eV}$ & \multirow[t]{2}{*}{ typ. 3.000-5.000 } \\
\hline & $8 \times 8 \mathrm{~mm}^{2}$ & typ. $133 \mathrm{eV}$ & \\
\hline \multirow{2}{*}{$\begin{array}{l}\text { PSD-30-145 } \\
\text { new technology }\end{array}$} & $30.0 \mathrm{~mm}^{2} \times 450 \mu \mathrm{m}$ & typ. $140 \mathrm{eV}$ & \multirow[t]{2}{*}{ typ. 3.000-5.000 } \\
\hline & $9 \times 9 \mathrm{~mm}^{2}$ & typ. $135 \mathrm{eV}$ & \\
\hline
\end{tabular}

We present various large area detectors and analyse their behaviour. The relevant detector parameters as signal capacitance and transistor conductances determining the electronic noise level are deduced from the measured performance and put into context with technical data. The results are discussed comparing single large area and multichannel devices and SDDs without integrated transistor. 


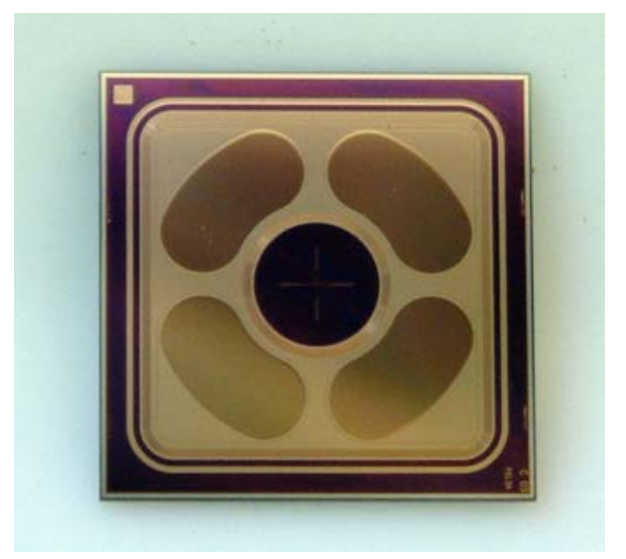

Fig. 1. A four element multichannel SDD with an overall area of $60 \mathrm{~mm}^{2}$ active area has been developed for large area high resolution purposes with an energy resolution of $130 \mathrm{eV}$ at $-20^{\circ} \mathrm{C}$. A hole cut in the middle of the device allows penetration of the exciting beam and a very close arrangement of probe and detector.

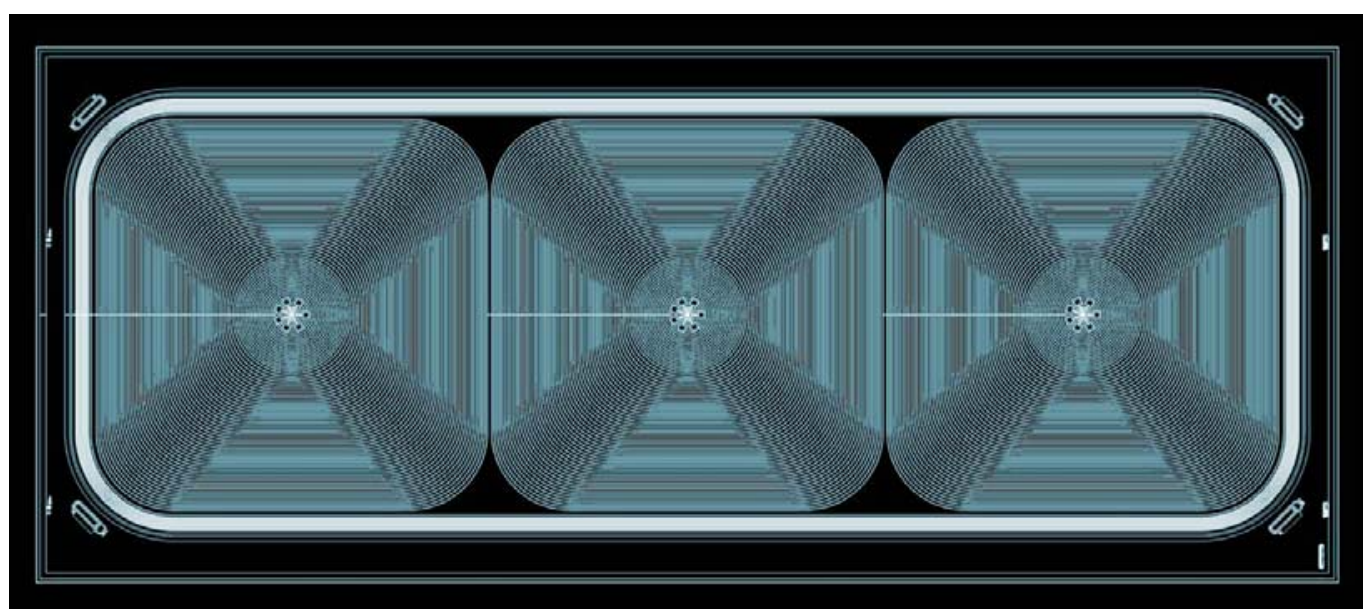

Fig.2. For the SIDDHARTA experiment in Frascati, Italy 70 SDD arrays with $3 \times 1 \mathrm{~cm}^{2}$ area are assembled to a barrel geometry to investigate the X-ray transitions of exotic atoms.

PSD-20-135 $\left(20 \mathrm{~mm}^{2}\right)$ - energy resolution vs. shaping time

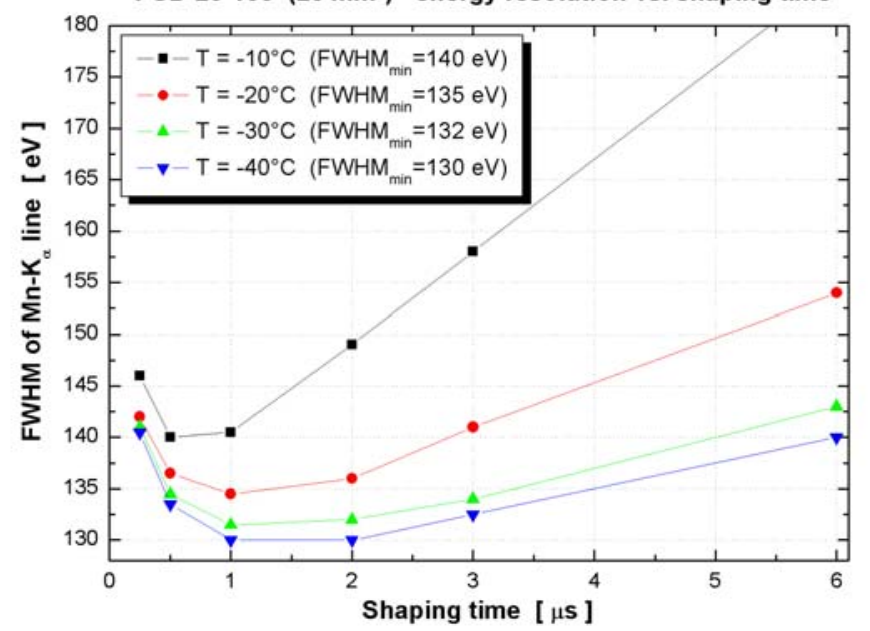

PSD-30-140 $\left(30 \mathrm{~mm}^{2}\right)$ - energy resolution vs. shaping time

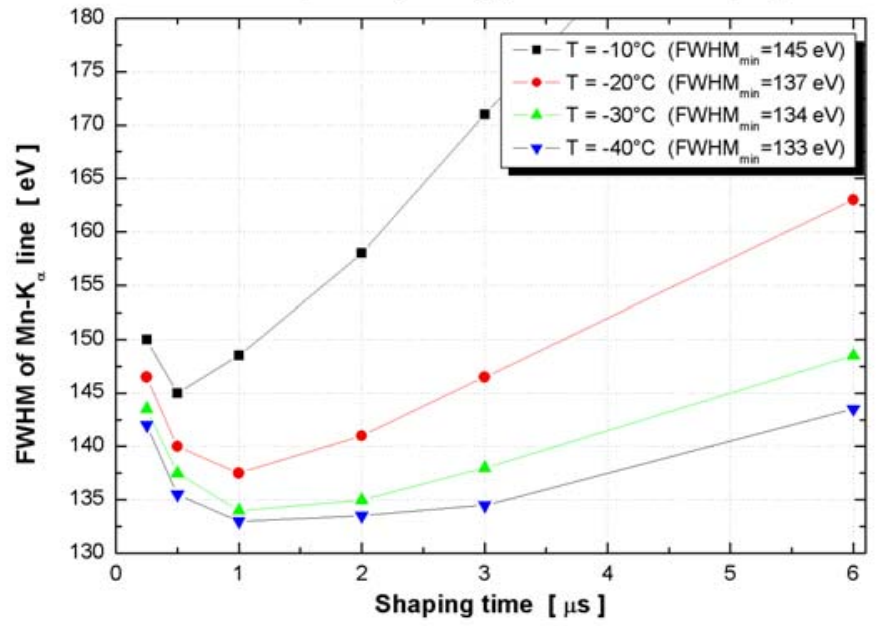

Fig.3. Energy Resolution of 20 and $30 \mathrm{~mm}^{2}$ SDDs. 